\title{
Comparison of tension wood and normal wood for oxidative nanofibrillation and network characteristics
}

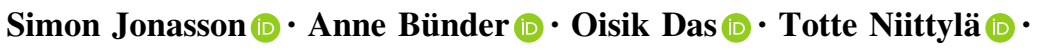 \\ Kristiina Oksman (D)
}

Received: 3 April 2020/Accepted: 23 October 2020/Published online: 12 November 2020

(C) The Author(s) 2020

\begin{abstract}
Cellulose nanofibrils (CNFs) are top-down nanomaterials obtainable from abundant lignocelluloses. Despite recent advances in processing technologies, the effects of variations in the lignocellulose structure and composition on CNF isolation and properties are poorly understood. In this study, we compared the isolation of CNFs from tension wood (TW) and normal wood (NW) from Populus tremula (aspen). The TW has a higher cellulose content, native cellulose fibrils with a larger crystalline diameter, and less lignin than the NW, making it an interesting material for $\mathrm{CNF}$ isolation. The wood powders were oxidized directly by 2,2,6,6-tetramethylpiperidin-1oxyl, and the morphology and mechanical behaviors of the nanofibril suspensions and networks were
\end{abstract}

Electronic supplementary material The online version of this article (https://doi.org/10.1007/s10570-020-03556-1) contains supplementary material, which is available to authorized users.

S. Jonasson · O. Das · K. Oksman $(\bowtie)$

Division of Materials Science, Luleå University of

Technology, Luleå, Sweden

e-mail: Kristiina.oksman@ltu.se

A. Bünder · T. Niittylä

Department of Forest Genetics and Plant Physiology, Umeå Plant Science Centre, Swedish University of

Agricultural Sciences, Umeå, Sweden

K. Oksman

Mechanical and Industrial Engineering, University of

Toronto, Toronto, Canada characterized. The TW was more difficult to fibrillate by both chemical and mechanical means. Larger nanofibrils $(5-10 \mathrm{~nm})$ composed of $1.2 \mathrm{~nm}$ structures were present in the TW CNFs, whereas the NW samples contained more of thin $(1.6 \mathrm{~nm})$ structures, which also comprised $77 \%$ of the solid yield compared to the $33 \%$ for TW. This difference was reflected in the TW CNF networks as decreased transmittance $(15 \%$ vs. $50 \%)$, higher degree of crystallinity $(85.9 \%$ vs. $78.0 \%)$, doubled toughness $\left(11 \mathrm{MJ} / \mathrm{m}^{3}\right)$ and higher elongation at break (12\%) compared to NW. The difference was ascribed to greater preservation of the hierarchical, more crystalline microfibril structure, combined with a more cellulose-rich network ( $84 \%$ vs. $70 \%$ ). This knowledge of the processing, structure, and properties of CNFs can facilitate the breeding and design of wood feedstocks to meet the increasing demand for nanoscale renewable materials. 

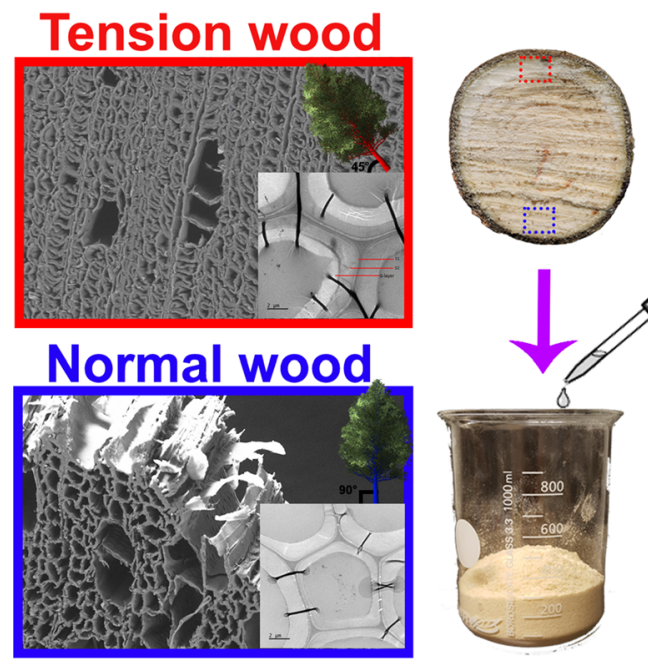
$\mathrm{O}=\mathrm{Cl} \mathrm{Na}{ }^{+} \mathrm{Br}$

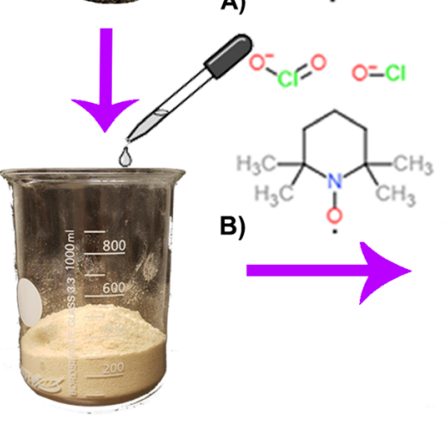

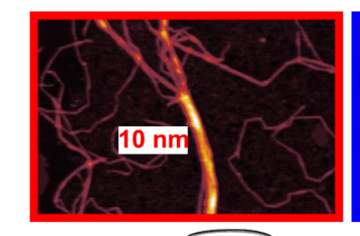
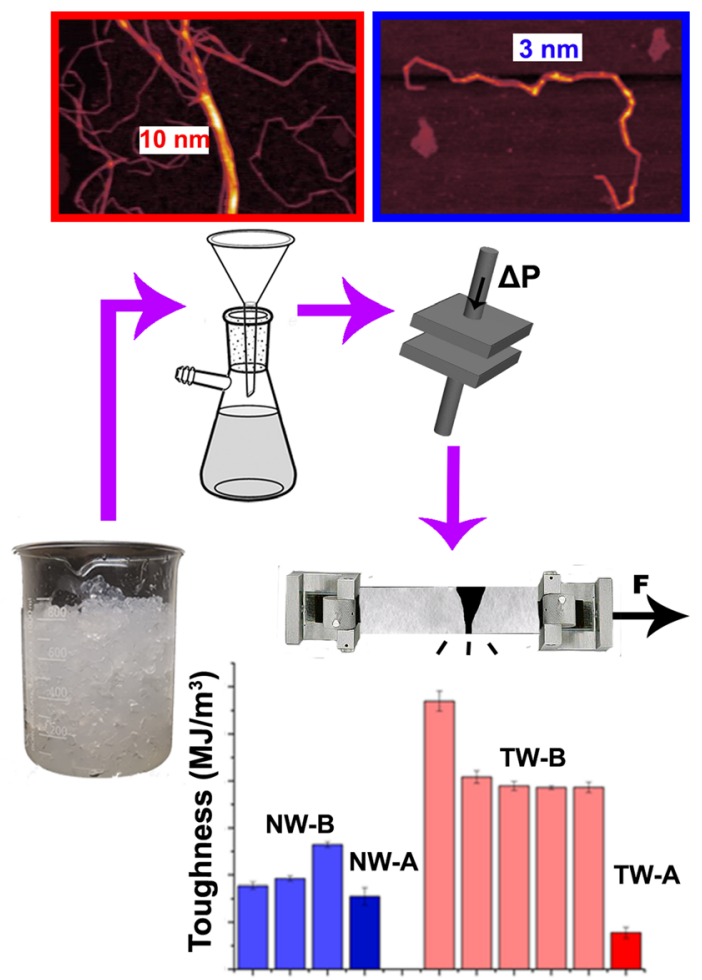

Keywords Cellulose nanofibril · Nanofibrillation · Fibril network - TEMPO oxidation · Tension wood . Wood properties

\section{Introduction}

Cellulose nanofibrils (CNFs) are high-aspect-ratio fibers isolated from the native cellulose microfibrils that comprise the cell walls of all plants. Research and applications of CNFs have increased rapidly, as demonstrated by the large increase in CNF-related publications and patents in the last decade (Charreau et al. 2013). Wood from managed forests and tree plantations is the largest source of cellulosic biomass, and potentially of CNFs, worldwide. Consequently, the isolation of CNFs from woody feedstock has attracted increasing attention. Increasingly efficient chemical pretreatment enables mechanical disintegration of wood pulps into CNFs. In particular, 2,2,6,6tetramethylpiperidin-1-oxyl (TEMPO) has proven effective in loosening the cell walls for enhanced fibrillation (Saito et al. 2007). Increased efforts have thus been made to exploit the nanoscale nature of the fibers for various applications, including high-volume/ low cost components and high-tech applications (Dufresne 2017). The perceived environmental drawbacks of established pretreatments (Jiang et al. 2017) have also driven the development of greener processing methods and materials, for example, deep-eutectic solvents (Li et al. 2017), ionic liquids (Li et al. 2012), and electro-mediated (Isogai et al. 2011) or laccasemediated TEMPO oxidation (Jiang et al. 2017).

The effects of each pretreatment on the CNF properties have been intensively studied to identify less expensive, greener processes or CNFs with improved performance. It may also be possible to obtain CNFs with different properties by exploiting the biological variation in the structure of the wood cell walls and cellulose microfibrils. For many CNF applications long crystalline cellulose chains are desirable. The tension wood (TW) of angiosperms is a potentially interesting raw material in this context. 
TW forms on the upper side of leaning stems in response to gravitational and mechanical forces (Felten and Sundberg 2013). In many species, including the aspen (Populus tremula), TW fibers develop a cellulose-rich gelatinous layer (G-layer) (Timell 1969) that contains cellulose microfibrils (CMFs) with significantly larger crystalline diameters than those of normal wood (NW) (Muller et al. 2006). The cellulose degree of polymerization (DP) is also higher in TW (Foston et al. 2011); this property is desirable for maximizing the mechanical properties of $\mathrm{CNF}$ networks (Henriksson et al. 2008). Owing to these attributes, TW is a potentially interesting raw material for CNF production and illustrates the genetic potential of breeding trees to obtain woody feedstocks with desirable CMF properties. Both the ultrastructural variation (G-layer) and the chemical composition (increased cellulose content) of TW have unknown effects on CNF isolation. The mechanical behavior of manufactured dry CNF networks is also influenced by many properties of the original CNFs (Meng and Wang 2019), which can serve as indicators of suitability for practical applications.

In this study, the extractability and properties of CNFs from NW and TW of $P$. tremula were compared. TW and NW were sampled and milled, and the woods were treated by direct oxidative treatments involving bleaching (acidified chlorite), mild $(\mathrm{pH}=6.8)$ and harsh ( $\mathrm{pH}=10.5)$ TEMPO-oxidation. The CNFs were obtained by simple stirring of the harshly TEMPOoxidized (chemically isolated) feedstock and by homogenization of the bleached (mechanically isolated) and mild TEMPO-oxidized (chemical-mechanically isolated) feedstocks. Fibril networks were then manufactured from each CNF suspension without further purification. The characteristics of the isolated CNFs (morphology, viscosity, chemical requirements, solid yield and nanofibril yield) and the fibril networks (transmittance, thermal behavior, crystalline properties, tensile properties and hardness) were investigated to determine the overall suitability for the woods for nanofibrillation and network performance. The aim of this study was to identify and understand how the cell wall composition and architecture affect CNF isolation process and physical behavior of corresponding networks. Knowledge of the processing and characterization of CNFs from woods with varying structure and composition can illuminate the role of biomass recalcitrance, and in turn what importance should be put on the resource need for fibrillating a feedstock vs. the final performance of manufactured materials.

\section{Materials and methods}

Chemicals for pulping and pretreatment

For bleaching and pretreatment, high-purity sodium chlorite (77.5-82.5\%), standard hydrochloric acid solution $(0.5 \mathrm{~N})$, standard sodium hydroxide solution $(0.1 \mathrm{~N})$, and sodium hydroxide beads ( $\geq 97 \%$, ACS) were purchased from VWR, Sweden. TEMPO (99\%), glacial acetic acid (100\%), sodium hypochlorite ( $\mathrm{NaClO}, 6-14 \%$ active chlorine), and sodium bromide ( $\geq 99 \%$ ) were purchased from Sigma-Aldrich, Sweden AB. All the chemicals were used as received.

Normal and tension wood sampling

TW and NW were manually cut from the sides of debarked forest-grown (two months' growth) aspen ( $P$. tremula) stems and cut into rectangular pieces $\left(\sim 1-2 \mathrm{~cm}^{3}\right)$. The sections were frozen in liquid nitrogen and milled into a wood powder to prevent heat degradation. Milling was performed using an A11 basic analytical mill (IKA-Werke, Germany) equipped with a chromium-carbide-coated stainless steel beater. Grinding was performed until a homogenous wood powder was obtained, which required a total grinding time of $2 \mathrm{~min}$. The powders were dried at $95{ }^{\circ} \mathrm{C}$ overnight, and their initial mass was determined before further processing.

\section{Chlorite bleaching of wood}

NW or TW (2 g) was submerged in water $(200 \mathrm{~mL})$, stirred for $24 \mathrm{~h}$, and then bleached using acidified (acetic acid) sodium chlorite (Wise et al. 1947). Three times, at $1 \mathrm{~h}$ intervals, $1 \mathrm{~g}$ of $\mathrm{NaClO}_{2} / \mathrm{g}_{\text {wood }}+0.2 \mathrm{~mL}$ of acetic acid were added. The bleached holocellulose was filtered and sonicated using an ultrasonic processor (Hielscher, Germany) at an amplitude of $40 \%$ for 15 min to loosen the wood cell aggregates and avoid excessive clogging during homogenization. 
Direct harsh TEMPO oxidation

The dried wood powder ( $2 \mathrm{~g}$ ) was submerged in water $(200 \mathrm{~mL})$ and stirred for $24 \mathrm{~h}$; then TEMPO $(35 \mathrm{mg})$ and sodium bromide $(0.2 \mathrm{~g})$ were dissolved in the slurry. The reaction was performed according to an established method at room temperature during continuous stirring (Saito et al. 2007). The reaction was initiated through addition of sodium hypochlorite (20.8 mmol) and hydrochloric acid to reach a $\mathrm{pH}$ of 10. Sodium hydroxide was added when the $\mathrm{pH}$ dropped to 9.7 to keep the $\mathrm{pH}$ between 9.7 and 10 . The reaction was terminated when the $\mathrm{pH}$ remained relatively constant. The wood powder was filtered, and two additional identical oxidations were performed for TW and NW. The final, relatively viscous suspensions ( $\sim 1$ wt. $\%$ ) were diluted to 0.17 wt. $\%$ and stirred before further characterization and production of the fibril networks. The CNF samples and the nanofibril networks produced via this direct oxidative method without mechanical fibrillation are denoted as NW-C or TW-C (where C indicates chemical treatment).

\section{Direct mild TEMPO oxidation}

The dried wood powder $(2 \mathrm{~g})$ was submerged in a phosphate buffer $(\mathrm{pH}=6.8)$ and stirred; then TEMPO (35 $\mathrm{mg}$ ) and sodium chlorite (20.6 g) at a temperature of $60{ }^{\circ} \mathrm{C}$ were dissolved in the solution. The reaction was initiated by adding sodium hypochlorite $(2 \mathrm{~mL})$ and stoppering the flask. The reaction was performed according to an established method during continuous stirring (Saito et al. 2009). Oxidation times ranging from 20 to $168 \mathrm{~h}$ were used to gauge the effect of direct oxidation of the wood powder, which is less accessible than wood pulp. The final swollen and delignified wood pulp was filtered and adjusted to a concentration of approximately 0.17 wt.\% before further processing and characterization. The CNF samples (and resulting networks) produced by this method are denoted as NW-CM or TW-CM (where $\mathrm{CM}$ indicates chemical-mechanical treatment) followed by the oxidation time $(20,42,72,120$, or 168 h), e.g., NW-CM42.

\section{Mechanical fibrillation}

Nanofibrillation was performed using an APV-2000 high-pressure homogenizer (APV, Denmark) with an average flow rate of $4 \mathrm{~mL} / \mathrm{s}$ at a suspension concentration between 0.20 and 0.17 wt.\%. The TEMPO/ $\mathrm{NaClO} / \mathrm{NaClO}_{2}$-treated wood powder was homogenized at 1000 bar with recirculation at a processing time corresponding to two passes or $35 \mathrm{kWh} / \mathrm{kg}$, as measured using a power meter (Carlo Gavazzi EM24 Din, Italy) on the basis of $1 \mathrm{~kg}$ of dry pulp. The holocellulose from the NW was processed at 100, 600, and 1000 bar (effective powers of 500, 700, and $850 \mathrm{~W}$ ) with 30,60 , and 10 passes; the cumulative energy usage corresponded to $0.8,2.5$, and $3.0 \mathrm{MWh} /$ $\mathrm{kg}$ after each sampling step, respectively. The energy per mass pulp $(\mathrm{kWh} / \mathrm{kg})$ was calculated as the product of the energy reading (W) and processing time (h) divided by the solid content of the suspension. Samples were taken after treatment at 100, 600, and 1000 bar, and are denoted as NW-M1, NW-M2, and NW-M3 (where M indicates mechanical treatment). Sampling was performed throughout processing to ensure that the relatively recalcitrant holocellulose had undergone sufficient fibrillation, as the holocellulose, unlike chemically derivatized wood samples, requires excessive mechanical energy to reach the appropriate degree of fibrillation.

\section{Solid and nanofibrillation yield}

The yield of the pretreated and fibrillated wood powders was characterized through measurement of (i) solid yield and (ii) nanofibrillated yield. Solid yield was calculated as the gravimetric yield after treatment of the wood which includes both fibrillated and less or non-fibrillated cellulose. To further characterize the amount of colloidally stable CNFs (highly nanofibrillated) the suspensions were centrifuged at 12,000 $\times g$ (Beckman Coulter J25i) for $20 \mathrm{~min}$ at an approximate consistency of 0.18 wt $\%$. The suspensions were decanted, and the solids retained in the sediment were dried for $24 \mathrm{~h}$ at $95{ }^{\circ} \mathrm{C}$. The nanofibrillated fraction was calculated according to the equation below (Eq. 1) where $m_{s}$ and $m_{t}$ is the dry sediment mass and total dry mass in the sample, respectively. The nanofibrillated fraction was reported as wt. $\%$ of the total dry wood mass, in a similar manner as the solid yield.

$$
\text { Nanofibrillated fraction }(w t . \%)=100 \times\left(1-\frac{m_{s}}{m_{t}}\right)
$$


Nanofibril network preparation

The CNF suspensions obtained by homogenization or chemical treatment were vacuum-filtered after $30 \mathrm{~min}$ of degassing in a vacuum oven. The degassed and homogeneous suspensions were filtered on a hardened filter paper (Whatman, grade 52). The cohesive networks (around 10-14\% solid content) were peeled from the filter and dried under ambient conditions while pressed between two blotting papers under a mass of $2 \mathrm{kN} / \mathrm{m}^{2}$. After $10 \mathrm{~h}$ of drying, the relatively homogeneous networks were dry enough to be hotpressed (Fontijne Grotnes LPC-300, Vlaardingen, Netherlands) between two mylar films without undergoing crushing due to excessive water content. Hotpressing was performed at $320 \mathrm{kN} / \mathrm{m}^{2}$ and $120{ }^{\circ} \mathrm{C}$. After the hot-pressing, the fibril networks were cut into $40 \mathrm{~mm} \times 5 \mathrm{~mm}$ specimens using a mechanical punch. The specimens were conditioned at $50 \% \mathrm{RH}$ for $\geq 48 \mathrm{~h}$ before further characterization.

\section{Viscosity}

The viscosity of the CNF suspensions was measured at a concentration of $0.18 \mathrm{wt}$.\% using a Vibro Viscometer (SV-10, A\&D Company Limited, Tokyo, Japan) with a tuning fork vibration method at a vibrational frequency of $30 \mathrm{~Hz}$. Viscosity was used to characterize degree of fibrillation when comparing the CNF suspension behavior from NW and TW.

\section{Polarized optical microscopy}

A Nikon Eclipse LV100 Pol (Kanagawa, Japan) polarized optical microscope with a $530 \mathrm{~nm}$ filter was used to characterize the nanofibrils and their networks (supplementary information) in order to study the morphology and identify larger cell wall residues. Polarized optical micrographs of the samples were recorded using a charge-coupled device camera.

\section{Atomic force microscopy}

Tapping-mode atomic force microscopy (AFM, Veeco MultiMode scanning probe, Santa Barbara, CA, USA) was used to analyze the morphology of the nanofibrils. Antimony-doped silicon cantilevers (TESPA-V2, Bruker) with a spring constant of $42 \mathrm{~N} /$ $\mathrm{m}$ and a nominal tip radius of $8 \mathrm{~nm}$ were used for the analysis. In the height analysis, the height response ( $z$ axis) was used to determine the height of the nanofibrils, whereas the $x$ and $y$ axes were used to determine the length of the nanofibrils, when applicable. All the samples were prepared by depositing a small droplet ( $0.001 \mathrm{wt} . \%)$ of a CNF suspension on a freshly cleaved mica plate and letting it air dry for $5 \mathrm{~h}$. The open-access software Gwyddion (Nečas and Klapetek 2012) was used for image correction by mean-plane subtraction and the removal of the polynomial (third-order) background. The nanofibril networks were also analyzed in a similar manner. The surface roughness of the fibril networks was analyzed using built-in software tools that calculate the rootmean-square (RMS) roughness of the surface peaks and valleys.

\section{Hemicellulose monosugar analysis}

To quantify the hemicellulose monosugar content, 500 $\mu \mathrm{g}$ of ball-milled wood material was first methanolyzed using $2 \mathrm{M}$ acetic acid/methanol, followed by silylation using a reagent mixture of 1,1,3,3,3-hexamethyldisilazane, trimethylchlorosilane, and pyridine at a molar ratio of 3:1:9. Derivatization was performed using the Sylon HTP kit (Supelco 33,038, SigmaAldrich) as previously described (Sweeley et al. 1963). The monosugar contents were determined using gas chromatography/mass spectrometry (7890A/5975C; Agilent Technologies, Santa Clara, CA, USA). The monosugar composition was analyzed to compare the hemicellulosic fraction of TW and NW.

UV-vis transparency

The transparency of the dried fibril networks was measured at a constant wavelength of $550 \mathrm{~nm}$ using a UV-vis spectrophotometer (GENESYS, 10 UV, Thermo Scientific, Schwerte, Germany). Three measurements were performed for each specimen, and data was presented in the form of transmittance (\%). Transparency was used as a metric of degree of fibrillation of the fibrils that comprises the final networks. 
X-ray diffraction

An x-ray diffractometer (PANalytical, Almelo, Netherlands) equipped with a PIXcel ${ }^{3 \mathrm{~d}}$ detector was used to measure the crystalline nature and degree of crystallinity of the dry CNF networks from NW and TW. $\mathrm{Cu}-\mathrm{K} \alpha$ radiation $(\lambda=0.154 \mathrm{~nm})$ was used during analysis with operation voltage of $45 \mathrm{kV}$ and a current of $40 \mathrm{~mA}$. A background (2-point, from $2 \theta=5$ to $2 \theta=40$ ) was subtracted from the spectrum whereafter the crystallinity index (CI) was calculated according to the peak height method (Segal et al. 1959). This was done through the equation below (Eq. 2), where $I_{200}$ is the intensity of the crystalline (200) peak at $2 \theta=22.4$, and $\mathrm{I}_{\mathrm{am}}$ is the intensity minimum between nearby crystalline peaks at $2 \theta=18$ where the contribution from the disordered cellulose fractions is thought to be the most representative (Park et al. 2010).

$C I(\%)=\frac{I_{200}-I_{a m}}{I_{200}} \times 100$

The crystallite size (D) of the samples were calculated according to the equation (Eq. 3) below (Scherrer 1918) where B is the full width at half maximum of the 200 peak in radians, obtained from a Pseudo-Voigt fit (OriginPro 8), $\lambda$ is the wavelength of the $\mathrm{x}$-rays $(1.54 \AA)$ and $\theta$ is the Bragg angle $(2 \theta=22.4)$.

$D=\frac{0.9 \lambda}{B \cos (\theta)}$

Tensile testing

The mechanical properties of the CNF networks were characterized using a Shimadzu AG-X universal testing machine (Kyoto, Japan) with a $500 \mathrm{~N}$ load cell. The conditioned specimens $(50 \% \mathrm{RH}, 40 \mathrm{~mm} \times$ $5 \mathrm{~mm}$ ) were $50-100 \mu \mathrm{m}$ thick (Table S1). Testing was performed at a cross-head speed of $10 \% / \mathrm{min}$, and the strain was measured using a video extensometer (high-speed camera, HPV-X2). The gauge length was set to $20 \mathrm{~mm}$ for each measurement. Six specimens were analyzed for each network batch. The tensile strength was reported as the maximum strength at break, the Young's modulus [the slope of the linear $\left(R^{2}=0.95-0.99\right)$ portion in the elastic region $(\approx 0.1-0.5 \%$ strain $)$, and the toughness [calculated area under the stress-strain curve (OriginPro 8 software)].

Nanomechanical properties

The nanomechanical characteristics (hardness and modulus) of the CNF networks were determined to analyze the properties perpendicular to the surface, in contrast to those in the parallel direction, which were obtained by tensile testing. Nanoindentation thus provides a different perspective on the mechanical behavior of the networks. A nanoindentation instrument (NanoTest Vantage, Micro Materials Ltd., UK) was used for testing. The nanofiber networks were glued to a mild steel cylinder using a cyanoacrylatebased super glue to stop the samples from moving during the indentation tests. The nanoindentation tip was a three-sided diamond Berkovich tip with a diameter of $50 \mathrm{~nm}$. The applied load was $20 \mathrm{mN}$ for each individual indentation, and the indenter contact velocity was set to $0.5 \mu \mathrm{m} / \mathrm{s}$. In all the experiments, the loading and unloading times were 20 and $15 \mathrm{~s}$, respectively. The dwell at maximum load was $2 \mathrm{~s}$, and the experiments were performed to obtain the depth vs. load hysteresis. A $3 \times 3$ indentation matrix $(9$ indents per sample) was applied to a flat surface identified by optical microscopy at a magnification of $20 \times$. The hardness and reduced modulus were obtained following a procedure described in previous studies (Das et al. 2015, 2019). The elastic modulus $\left(E_{\mathrm{s}}\right)$ of the samples was calculated from the reduced modulus $\left(E_{\mathrm{r}}\right)$ using the following formula (Eq. 4):

$\frac{1}{E_{r}}=\frac{1-v^{2}}{E_{s}}+\frac{1-v_{i}^{2}}{E_{i}}$

where $v$ is the Poisson's ratio of the sample, which was assumed to be 0.3 ( $\mathrm{Wu}$ et al. 2010); $v_{\mathrm{i}}$ is the Poisson's ratio of the indenter tip (0.07), and $E_{\mathrm{i}}$ is the modulus of the indenter tip (1140 GPa).

\section{FTIR}

FTIR analysis of the prepared networks (supplementary information) was performed using a PerkinElmer Spectrum 2000 instrument (Waltham, MA, USA) equipped with an attenuated total reflectance system. Each network was scanned 128 times at wavenumbers of $4000-400 \mathrm{~cm}^{-1}$ at a resolution of $4 \mathrm{~cm}^{-1}$. 


\section{Results and discussion}

TEMPO oxidation of wood samples

The $\mathrm{NaOH}$ consumption versus time during the oxidation of TW and NW is shown in Fig. 1a; the rate and amount consumed for both types of wood were initially similar. This result was attributed to delignification, which is apparent from increased whiteness before the second titration (Fig. 1b). The second step allowed for more oxidation as the wood cells were separated more and cellulose accessibility
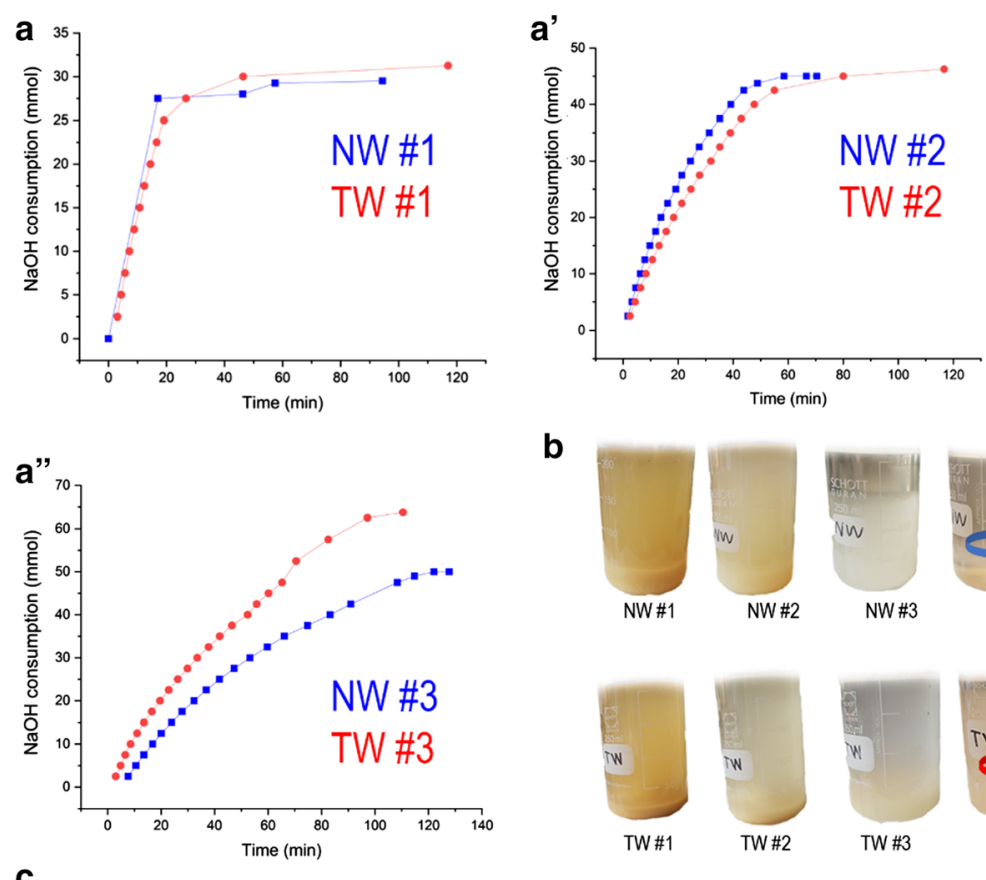

b
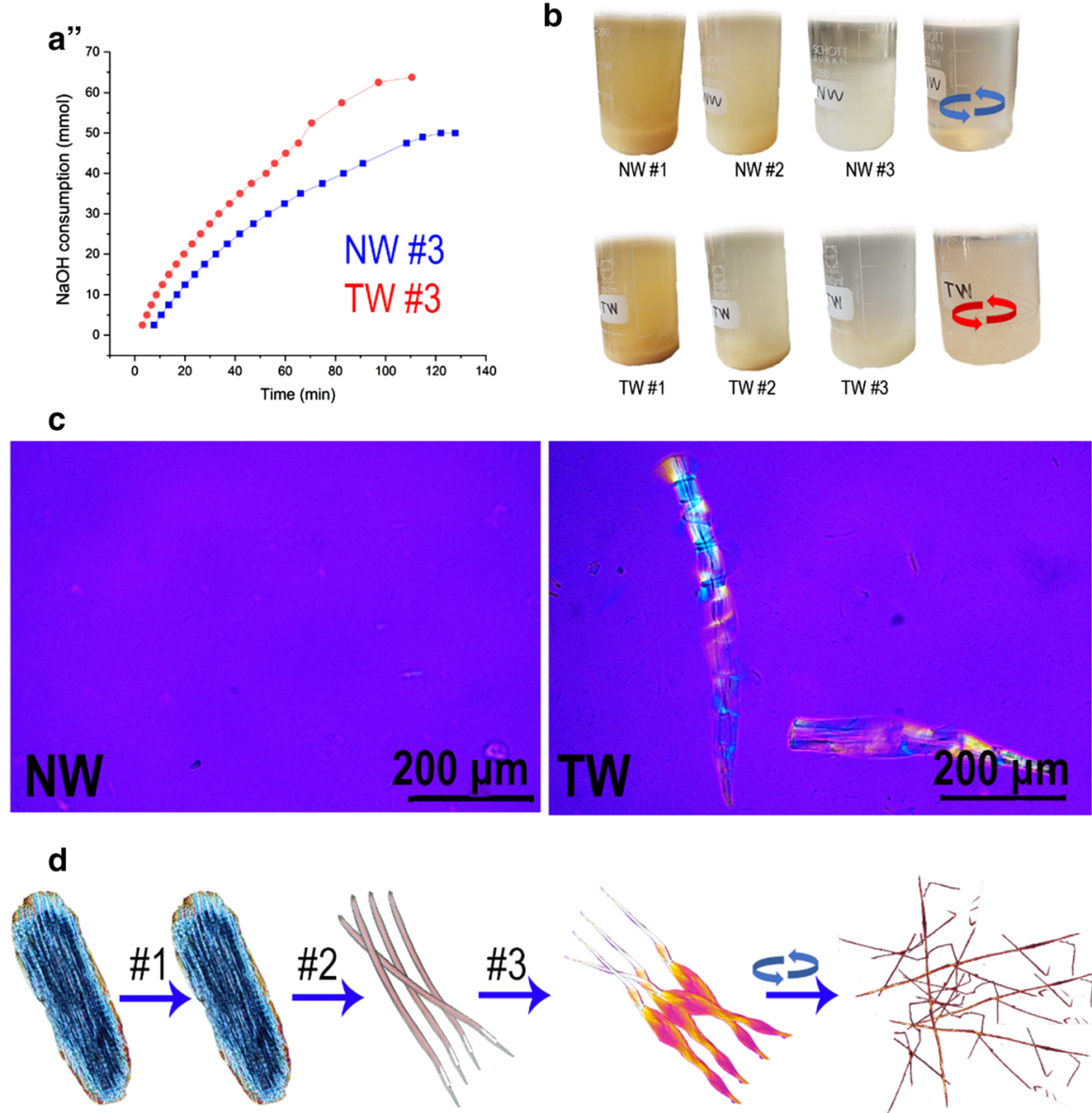

Fig. 1 Kinetics of the TEMPO/ $\mathrm{NaBr} / \mathrm{NaClO}$ system during oxidation of wood powder from NW (blue) and TW (red). a The three subsequent oxidation events versus time (a-a") and b visual appearance of each type of wood and titration run. c Representative optical micrographs of the suspensions after

the third titration, which reveal the retention of cell wall structures in the TW. d Schematic illustration of fibril isolation from wood particles in response to TEMPO/ $\mathrm{NaBr} / \mathrm{NaClO}$ oxidation of wood powder where liberation of wood fibers is followed by swelling and spontaneous fibrillation 
increased where the $\mathrm{NaOH}$ consumption increased from approximately $28-45 \mathrm{mmol}$. The largest differences appeared after the third oxidation, where both the rate and absolute consumption were higher for TW (65 mmol NaOH consumed) than for NW (47 mmol). In addition, the NW suspension showed high viscosity and transparency (Fig. 1b) after the third oxidation step (Fig. 1a“), indicating that high-aspect-ratio nanofibrils were isolated (Iwamoto et al. 2014). TW suspension showed high colloidal stability, and the dispersion was maintained over time, as expected for carboxylated samples, but larger nanofibrils and cell wall residues were still present (Fig. 1b, c). This indicates that the cellulose from TW is less accessible and has higher chemical requirements in order to facilitate greater carboxylation and subsequent disintegration of the wood cell walls. This finding can be attributed to the increased crystallinity and higher relative cellulose content of TW (Al-Haddad et al. 2013; Gorshkova et al. 2015). The structural integrity of the cell walls is thus likely to be maintained to a larger extent during a TEMPO-catalyzed oxidation process. Considering the amount of $\mathrm{NaClO}$ that was used (21 mmol per oxidation), it is also noteworthy that the NW showed no signs of incomplete fibrillation during this purely chemical treatment, even though the NW contained more lignin. This is shown in Fig. 1c where light micrographs show no residual wood cells or larger aggregates, like those seen in TW samples. Lignin is known for being responsible for biomass recalcitrance in wood, though the results here indicate that a higher cellulose content and reduced accessibility for TW contributes to a larger extent and slows down oxidative nanofibrillation. This is in contrast to biofuel production where TW has been described as being less recalcitrant due to reduced lignin content (Foston et al. 2011).

\section{Cellulose and nanofibril properties}

The characteristics of the isolated cellulose and nanofibrils after chemical [as previously shown (NW-C,TW-C)], mechanical (NW-M), and chemical-mechanical (NW-CM, TW-CM) processing are presented in this section, including the solid yield, nanofibril yield, monosugar composition of the hemicellulose fraction of the initial wood samples, morphology (AFM), and degree of fibrillation (viscosity).

\section{Cellulose and nanofibril yield}

The cellulose and CNF yields of each processing route are shown in Fig. 2. The mechanically treated wood (NW-M and TW-M) had the highest solid yield, and the material obtained from each wood sample is identified as holocellulose, as the only yield-affecting process was chlorite bleaching. The fraction of finer CNFs from NW-M and TW-M are negligible, attributed to the lack of chemical derivatization prior to fibrillation which leaves larger microfibril aggregates intact. The TW solid yields after oxidation are significantly higher at $64.9 \pm 9$ wt. $\%$ vs. $50.7 \pm 7$ wt.\% for NW. The yield after purely chemical treatment (NW-C and TW-C) was lower for NW and only slightly below the mean for TW. A difference in the yield of highly fibrillated CNFs was found where a larger portion of the solids obtained from NW turned into CNFs after chemical and chemical-mechanical treatments compared to TW. $72 \pm 11$ wt. $\%$ and $33 \pm 10$ wt. $\%$ of the total process yield turned into highly nanofibrillated CNFs for NW and TW, respectively. The yield of these CNFs relative total dry wood was $32 \pm 4$ wt. $\%$ and $21 \pm 2$ wt. $\%$ for NW and TW.

The high solid yields for TW can be attributed to the fact that TEMPO oxidation tends to retain all the cellulosic solids (Isogai and Kato 1998), as well as the

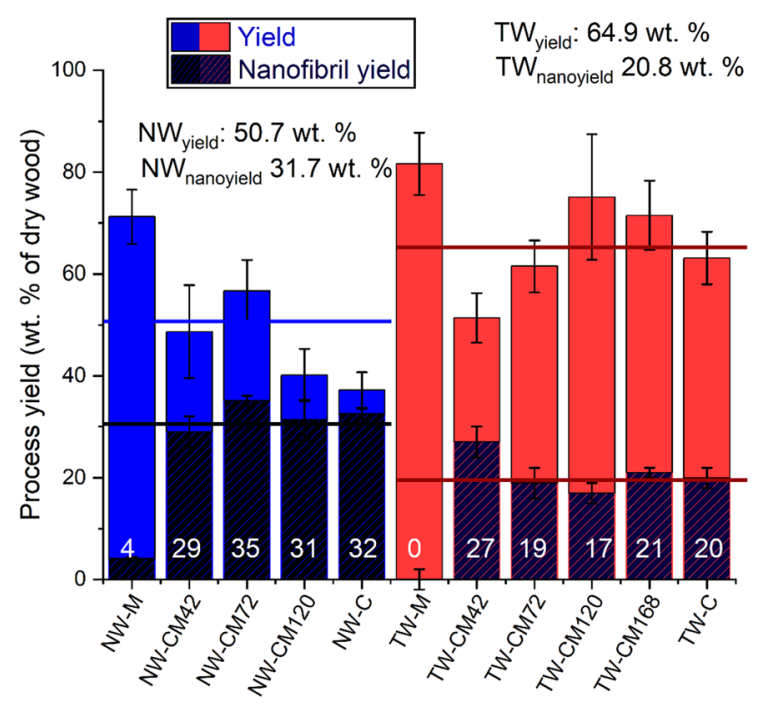

Fig. 2 Solid and nanofibril yields from TW and NW in each processing step. Lines show the overall mean yields for TW (red) and NW (blue) throughout the study 
overall higher cellulose content and lower hemicellulose and lignin content of aspen TW compared to NW (Gorshkova et al. 2015). The higher fraction of CNFs for NW compared to TW is furthermore supported by the results presented previously in Fig. 1 where an increased recalcitrance for TW also is indicated in this CNF yield analysis.

\section{Monosugar analysis}

Aspen wood contains 45-52\% cellulose, 20-28\% hemicellulose, and 20-24\% lignin (Pettersen 1984). Hemicellulose has been proposed to influence both yield and nanofibrillation efficiency of wood cellulose (Iwamoto et al. 2008). This makes it interesting to analyze in the context of comparison of NW and TW. The main hemicellulose in aspen is glucuronoxylan (with a backbone of O-acetyl-4-O-methylglucuronoB-D-xylan) and glucomannan [with a backbone of $\beta(1-4)$-linked D-mannopyranose and D-glucopyranose]. The TW of aspen reportedly contains some galactan, with a backbone of $\beta$-(1-4)-linked D-galactopyranose units, which are heavily substituted at the C6 hydroxyl group with galactose units (Linow 1985). The TW galactan also contains 4-O-methyl-D-glucuronic acid, D-glucuronic acid, D-galacturonic acid, L-rhamnose, and L-arabinofuranosyl residues.

The monosugar composition of the hemicellulosic fraction of the NW and TW in this study is shown in Table 1 . TW clearly contains significantly less xylose and more glucose. This finding is likely to be related to the increased cellulose content of TW owing to the presence of the cellulose-enriched G-layer (Donaldson and Singh 2016). Although glucose from cellulose should be preserved during the analysis, it is likely that some glucose from the disordered cellulosic portion of the wood was hydrolyzed during sample processing. TW also has significantly less mannose and more galactose. These observations are in agreement with a previous report on the composition of poplar TW (Gorshkova et al. 2015).

\section{Nanofibril morphology and fibrillation behavior}

Thin CNFs (1-3 nm) resembling elementary fibrils and lower hierarchies were readily accessible after chemical-mechanical processing of each type of wood. Interestingly, the CNFs isolated from TW had
Table 1 Monosugar composition (wt.\%) of the hemicellulose fraction of the initial wood samples

\begin{tabular}{lrc}
\hline Monosugar & \multicolumn{1}{l}{ TW } & NW \\
\hline Arabinose & $0.8(0.1)$ & $0.5(0.1)$ \\
Rhamnose & $1.4(0.1)$ & $1.4(0.0)$ \\
Fucose & $0.1(0.0)$ & $0.14(0.0)$ \\
Xylose & $60.7(2.2)$ & $72.6(0.6)$ \\
Mannose & $0.8(0.0)$ & $5.7(0.3)$ \\
4-O-meGlcA & $2.2(0.0)$ & $5.1(0.2)$ \\
Galactose & $2.4(0.1)$ & $0.6(0.1)$ \\
Galacturonic acid & $3.7(0.1)$ & $3.3(0.2)$ \\
Glucose & $27.7(2.4)$ & $10.4(0.3)$ \\
Glucuronic acid & $0.05(0.0)$ & $0.05(0.0)$ \\
\hline
\end{tabular}

Standard deviation in brackets $(\mathrm{n}=3)$

lower (pairwise t-test, $p<0.05$ ) cross-sectional diameters than those from NW. Figure 3 shows the size distributions and atomic force micrographs with heights. The TW and NW were found to have average heights of 1.2 and $1.6 \mathrm{~nm}$, respectively. Under ambient conditions, the resolution of AFM is as low as $0.1 \mathrm{~nm}$ (Gan 2009), which supports the validity of the observed statistical difference. CNFs with absolute sizes in similar ranges have also been reported using similar methodologies regarding chemical treatments (Li and Renneckar 2009, 2011; Usov et al. 2015; Geng et al. 2018; Mendoza et al. 2018). The relatively small scale of the CNFs were hypothesized to be from cleavage of the native fibrils into smaller structures than the $3 \mathrm{~nm}$ elementary fibrils. In support of this interpretation similar fibril dimensions as observed here were recently reported for in vitro produced cellulose from a plant cellulose synthase complex (Purushotham et al. 2020). The difference in height (Fig. 3) can thus be interpreted as a difference in how the crystalline cellulosic structures fragment in relation to chemical-mechanical treatment of the feedstock.

According to previous studies the diameters of microfibrils from TW are reportedly four times larger than those of microfibrils from NW (Müller et al. 2006). This has been attributed to differences in microfibril aggregation and the mechanisms of cellulose crystallization (Mellerowicz and Gorshkova 2011). TW elementary fibrils were found to aggregate into larger crystallites compared to NW (Sawada et al. 

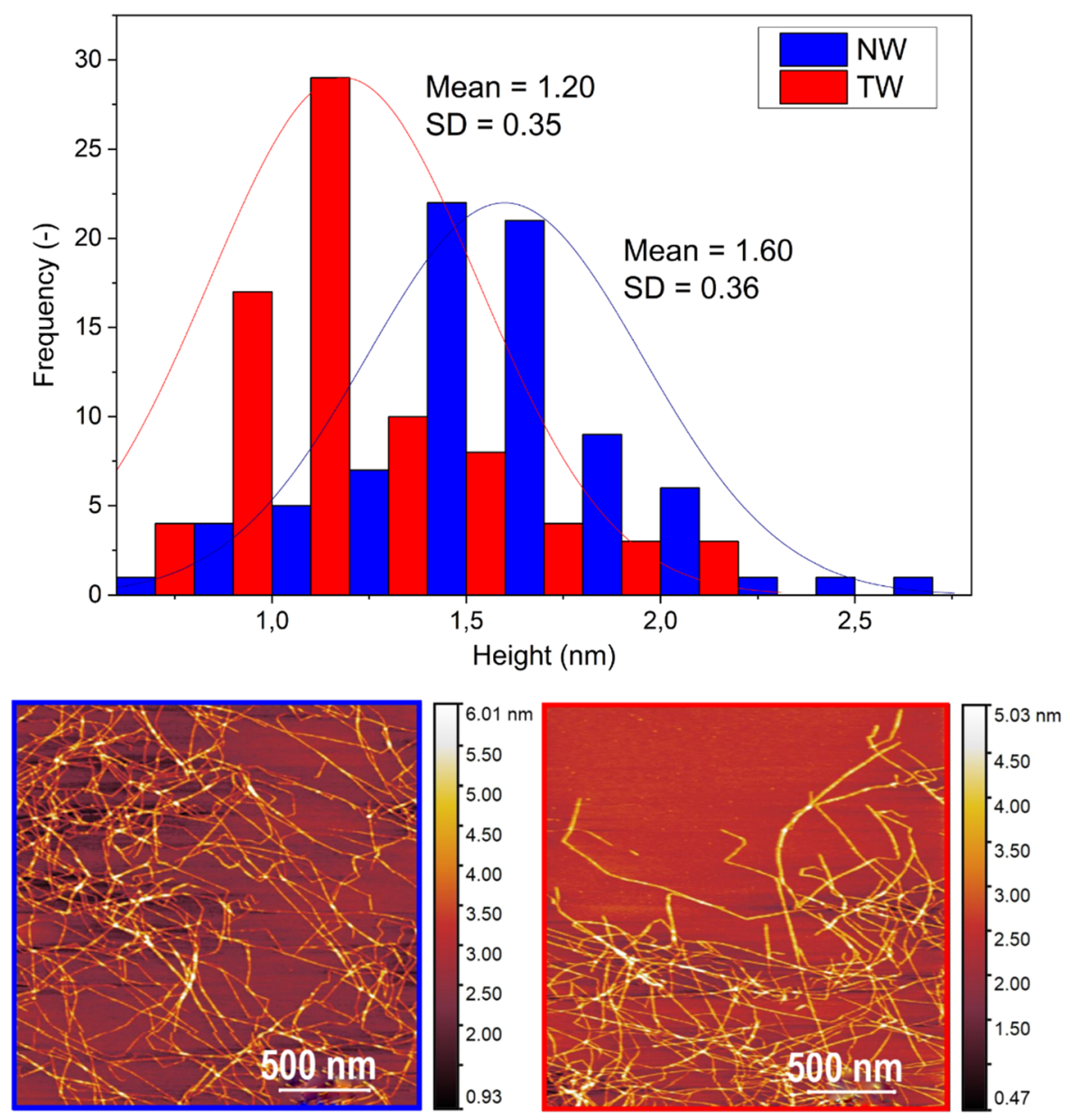

Fig. 3 Size distribution (top) of the prominent CNFs isolated from NW (blue) and TW (red) with corresponding AFM micrographs (bottom)

2018). In this study we also report on similar structures. Figure 4 shows representative images of these structures as well as the viscosity of NW and TW CNF suspensions. Viscosity values range between 10 and $22 \mathrm{mPas}$ for NW-CNFs and 2-7 for TW-CNFs which implies a greater degree of fibrillation for NWCNFs due to the presence of higher aspect ratio nanofibrils (Iwamoto et al. 2014). This is also supported by the CNF yield (Fig. 2) where a larger percentage of the total solids for NW-CNFs is comprised of thinner nanofibers. Especially in the case of NW-CM120 where both nanofibril yield and viscosity goes higher than average.

The presence of 3-10 nm nanofibrils is apparent in the case of TW-CM. A $10 \mathrm{~nm}$ structure that consists of individual fibrils with distinct sizes of $1.5,3$, and $5 \mathrm{~nm}$ is highlighted below. The $5 \mathrm{~nm}$ fibrils could correspond to fibrils similar to the sizes of the native crystallite size, which have been identified at $4.4 \mathrm{~nm}$ from WAXD (Sawada et al. 2018). These aggregates were furthermore not observed in NW samples. Fragmented aggregates consisting only of two or three distinct structures, at most, were observed in the NW (Fig. 4). Aside from the obvious kinking, the variation between 3 and $1.5 \mathrm{~nm}$ within the same structure also corroborates previously mentioned fragmentation, where the $3 \mathrm{~nm}$ regions corresponds to the native state of the elementary fibrils.

To further understand the fragmented appearance of the nanofibrils in Fig. 4, we identified regions of obvious fibrillation phenomena. Figure 5 shows the initial state of a nanofibril (3-4 nm) from NW that consists of three thinner structures $(1.7 \mathrm{~nm})$. In two 

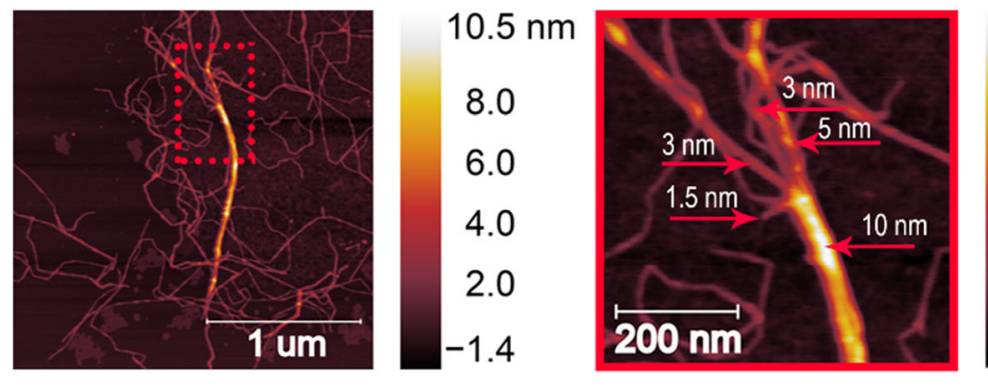

$11.2 \mathrm{~nm}$
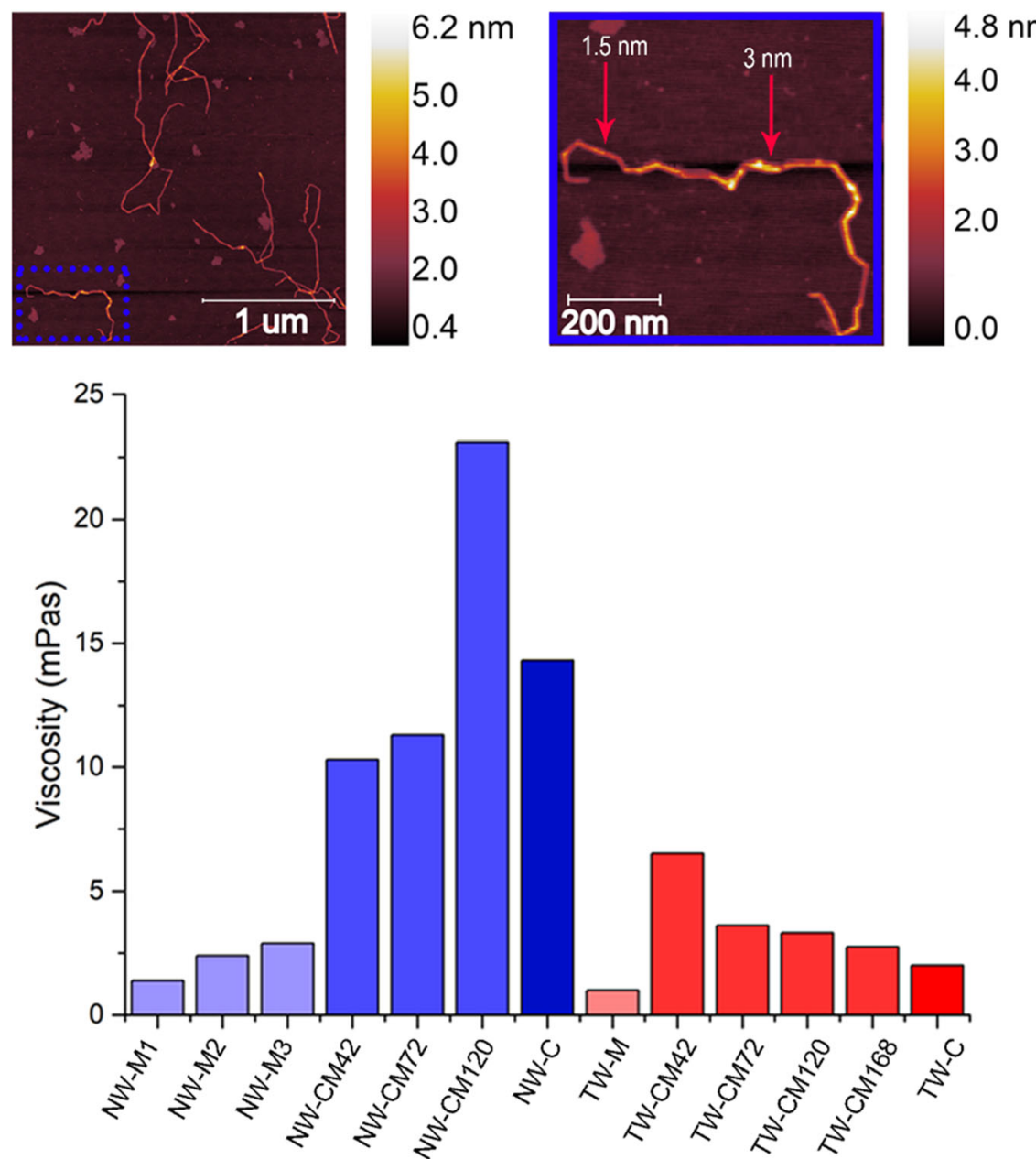

Fig. 4 Fibrillation behavior of CNFs from NW and TW. TW (upper images) forms smaller nanofibrils of distinct sizes emerging from a fragmented larger nanofibril. NW (lower

regions, partial delamination/cleavage (grey arrows) of a double aggregate (white arrow) comprising of two smaller structures is apparent. In the other region there is total delamination (kinking) of the same type of small structure (black arrow). This observation indicates that the thinnest structures that we observe in this images) forms a separate nanofibril consisting in part of short segments of larger aggregates. The graph shows the viscosity of NW and TW-CNF suspensions (0.18 wt.\%)

study are wound around each other in a right-hand twisting fashion, which is further supported by the height fluctuation along the nanofibril direction for an aggregate consisting of two fibrils (Fig. 5a). Indeed, this fluctuation indicates a periodicity which is related 


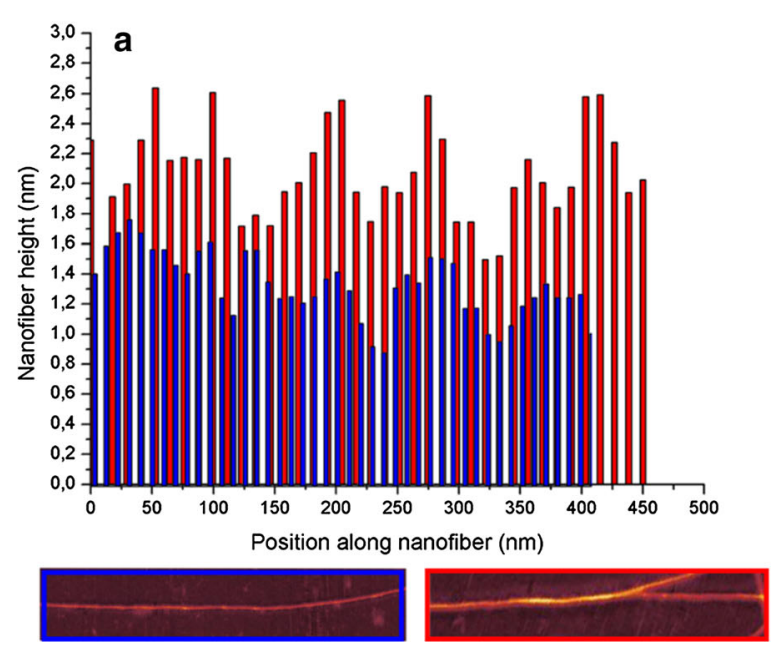

Fig. 5 a Representative height fluctuations of nanofibrils from NW along nanofibril $(0-500 \mathrm{~nm})$ for an individual thin CNF (lower left) and corresponding double aggregate (lower right).

to the twisting nature of both smaller and larger nanofibrils (Usov et al. 2015).

Physical properties of nanofibril networks

The characteristics of the manufactured fibril networks, including the morphological, thermal, crystalline and mechanical properties, are presented in this section.

\section{Surface morphology and transparency}

Visual appearance, AFM micrographs and SEM micrographs of representative networks from TW and NW are presented below together with corresponding transparency (Fig. 6). The surface morphology and the transparency of the fibril networks differed greatly; all the nanofibril networks derived from TW CNFs showed lower transparency than those obtained from the corresponding NW CNFs (Fig. 6d). In addition, the transparency of the TW CNFs increased slightly with increasing oxidation time, whereas that of the NW CNFs exhibited the opposite behavior. From AFM (Fig. 6b) it is furthermore apparent that networks from TW CNFs have higher surface roughness; the RMS roughness values of the TW and NW CNF networks are 7.3 and $2.6 \mathrm{~nm}$, respectively. However, the micrographs do not show

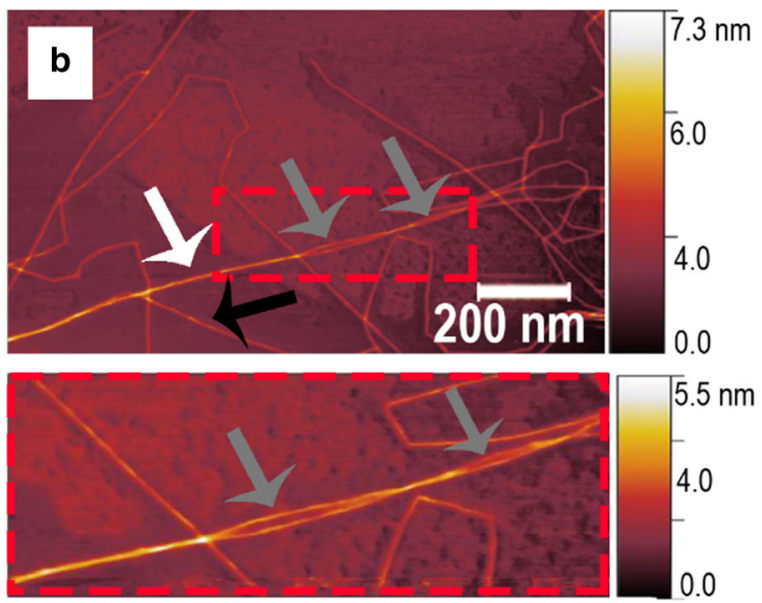

b AFM micrograph. The arrows indicate nanofibrils showing kinking (black) and partial delamination (gray arrows) with the initial double aggregate (white)

many large nanofibrils, which would directly explain both the decreased viscosity (Fig. 5) and the decreased transparency (Fig. 6). The reason is that the large nanofibrils appear among a much larger number of smaller nanofibrils, which explains these characteristics, as well as the increased roughness of the TW CNF network, where the surface roughness results from the presence of larger nanofibrils and aggregates beneath the surface. The more abundant small nanofibrils (1-3 nm) would also appear as a coating on the larger $(>10 \mathrm{~nm})$ ones. Furthermore, the mean densities (Table S1) of the fibril networks are very similar $\left(1.23 \pm 0.02\right.$ and $1.21 \pm 0.04 \mathrm{~g} / \mathrm{cm}^{3}$ for the TW and NW networks, respectively) with corresponding appearance (through SEM) that reveal dense network characteristics (Fig. 6c). This rules out a significant contribution to the transparency from variations in porosity. In addition, the average thicknesses (Table S1) of the networks were quite similar at $71 \pm 16$ and $76 \pm 6 \mu \mathrm{m}$ for the TW and NW networks, respectively.

\section{Thermal analysis}

The thermogravimetry and differential thermogravimetry (DTG) curves of the samples (Fig. 7) show three types of thermal stability depending on the degree of oxidation. In agreement with other studies of 

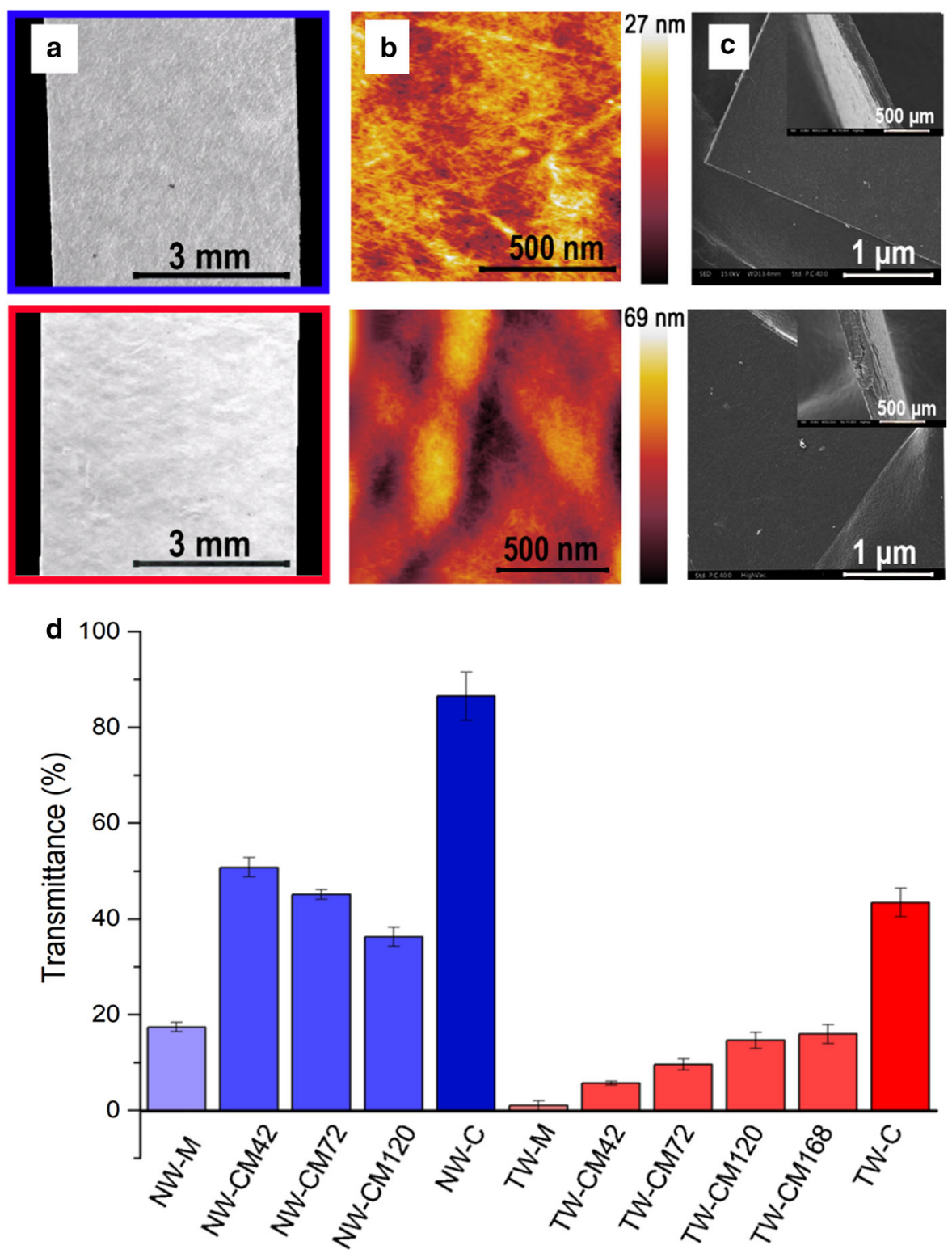

Fig. 6 Physical properties of dried nanofibril network from NW CNFs and TW CNFs: a visual appearance, with variations in turbidity apparent (top: NW CNFs, bottom: TW CNFs), b AFM images of network surfaces with variation in roughness, c SEM

wood-derived cellulose and TEMPO-oxidized CNFs, the thermal stability decreases with increasing oxidation time (Lichtenstein and Lavoine 2017). The bleached wood cellulose degrades in a narrow interval, as indicated by one distinct peak in the DTG graph. For TW-CM and NW-CM, two degradation events appear; the first $\left(\mathrm{T} \approx 250{ }^{\circ} \mathrm{C}\right.$ ) is from decarboxylation, which occurs because more carboxyl groups are images of surfaces and cross sections of the networks, revealing their characteristic dense appearance $\mathbf{d}$ transparency of the networks $(\lambda=550 \mathrm{~nm})$

present on the nanofibril surfaces (Fukuzumi et al. 2010), resulting in the formation of carbonyl compounds and aromatization. Collapse of the glycosidic structure has been suggested at $250-350{ }^{\circ} \mathrm{C}$ (Lichtenstein and Lavoine 2017). Interestingly, the second peak $\left(T \approx 320^{\circ} \mathrm{C}\right.$ ) for TW-CM and NW-CM disappears upon further oxidation (TW-C and NW-C). At more extensive oxidation, the samples likely 

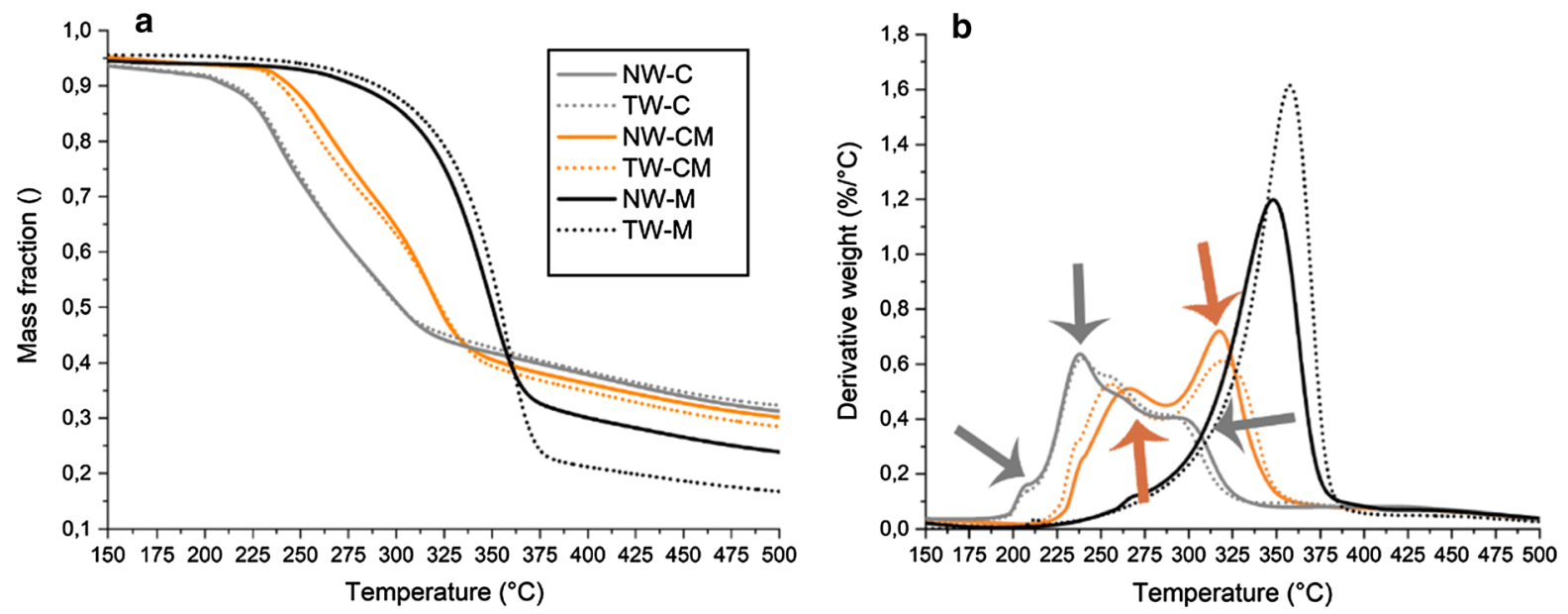

Fig. 7 Thermal degradation curves showing mass loss (a) and derivative weight (b) with degradation events highlighted (arrows) for NW/TW-C and NW/TW-CM

approached the initial decarboxylation step, which seems to appear as a shoulder at the end of the main initial degradation event for TW-C and NW-C $\left(T \approx 250^{\circ} \mathrm{C}\right.$,). In addition, TW-M exhibits slightly greater thermal stability than NW-M, as the temperature of peak degradation of TW-M is $10{ }^{\circ} \mathrm{C}$ higher than that of NW-M. The more oxidized NW and TW samples do not exhibit these differences. In fact, TWCM seems to exhibit lower thermal stability than NWCM. Three degradation events appear for TW-C and NW-C (see grey arrows, Fig. 7) where the shoulder close to $207{ }^{\circ} \mathrm{C}$ is related to early decarboxylation events (Lichtenstein and Lavoine 2017).

\section{$X$-ray diffraction}

The x-ray diffractograms of networks made from TWCNFs and NW-CNFs are presented below (Fig. 8) and reveal a similar cellulose I crystal structure as native cellulose that comprise wood (Andersson et al. 2003). Larger degree of crystallinity for TW-CNFs than NWCNFs (85.9\% vs. $78.0 \%$ ) with a corresponding increase in crystal size diameter can be seen where the crystallites for TW approaches $4.0 \pm 0.1 \mathrm{~nm}$ compared to the $3.5 \pm 0.1 \mathrm{~nm}$ of NW. These values agree with observations that TW-fibrils are thicker and more crystalline than those from NW (Sawada et al. 2018). The XRD data also supports previously shown presence of fibril aggregates (Fig. 4). Interestingly, the relation between dimensions of the crystallites from
XRD does not seem to correlate with the dimensions obtained for the individual fibrils from AFM. This has been reported previously and was explained in part due to the preservation of the $I_{\beta}$ structure, though with a reduction in crystallinity due to the fragmentation at the (200) plane (Li and Renneckar 2011). Some of the fibrils that were shown in Figs. 3, 4 and 5 would according to this hypothesis thus be fragments of the larger crystallites, for both NW and TW.

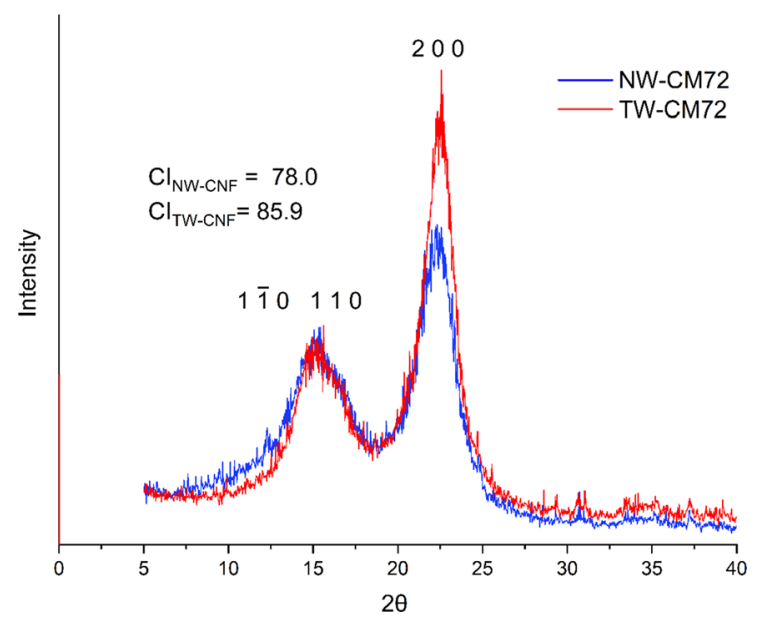

Fig. 8 X-ray diffractograms of representative CNF networks made from NW-CNFs (blue) and TW-CNFs (blue). The degree of crystallinity as determined using the height method is also shown 


\section{Tensile properties}

Figure 9 shows the mechanical properties of the nanofibril networks. The most prominent differences between the TW and NW samples is that the TW CNF networks show higher toughness and elongation at break than the NW CNF networks. The elongation at break and toughness reach $11.6 \%$ and approximately $11.4 \mathrm{MJ} / \mathrm{m}^{3}$, respectively, for the fibrils prepared with a short oxidation time (TW-CM20), whereas those of the NW CNF network reach maximum values of 5.5\% and $5.3 \mathrm{MJ} / \mathrm{m}^{3}$, respectively, for NW-CM120. The stiffness and ductility of TW-CM also change with the oxidation time, where the fibril network is initially flexible and tough but becomes more brittle and stiff. This is especially apparent for TW-CM20, which indicates that there is an optimal oxidation time for a given wood sample. As a result, the CNFs form networks that differ greatly in tensile behavior even after relatively short oxidation times. Similar behavior with respect to the oxidation time was not found to be statistically significant for the NW-CM series (see the supporting information, table S2-S6, for Tukey's HSD output).

The chemically treated NW sample exhibited the most brittle and stiff networks. The brittleness can be explained by a large reduction in the DP due to treatment with TEMPO/ $\mathrm{NaBr} / \mathrm{NaClO}$ (Shibata and Isogai 2003). The more fibrillated samples have higher moduli, which have been attributed to increased interfiber bonds within the network (Mao et al. 2017) The fibril networks in TW-C, in contrast to those in NW-C, have poor mechanical properties overall owing to the presence of micron-sized residues (fines and wood cell wall fragments), which act as defects. The mechanical properties of the nanofibril network from the mechanically treated CNFs (NW-M) are lower than those of the chemically-mechanically treated (NW-CM) and chemically treated (NW-C) networks. A similar phenomenon has been observed previously (Jonasson et al. 2020) and indicates the importance of pretreatment before homogenization to obtain enhanced network properties. Enhanced toughness, which was observed in the TW CNF networks, has also been observed for nanofibril networks of high-DP CNFs, both experimentally (Henriksson et al. 2008; Fukuzumi et al. 2013) and theoretically (Meng et al. 2017). The nanofibril length is preserved in these CNFs
(Shinoda et al. 2012) and thus supports network formation, resulting in a higher elongation before failure. This phenomenon has been attributed to an increase in hydrogen bonds between the CNFs (Zhu et al. 2015).

Other factors that reportedly affect the toughness of the networks are (1) the smaller diameter of the CNFs (Zhu et al. 2015), (2) the porosity (Jonoobi et al. 2012), (3) the moisture content (Benítez et al. 2013), (4) the orientation of the CNFs (Sehaqui et al. 2012), (5) the hemicellulose/lignin content (Meng and Wang 2019) and (6) structural differences due to origin of the feedstock (Stelte and Sanadi 2009). In this study, the difference in feedstock structure (G-layer) and hemicellulose/lignin content are likely the main reasons for the differences between the TW and NW networks. It is important to note the variations in the composition of the networks, where hemicelluloses often comprise a significant portion of the CNF suspension. The increased hemicellulose content reportedly interferes with CNF network formation, reducing the toughness and tensile strength (Arola et al. 2013). This effect could explain the large variation in toughness between the TW and NW networks. To investigate this effect, the tested networks were submerged in $\mathrm{NaOH}$ to extract the hemicellulose (Fig. 10); it was found that the TW CNFs contain $\leq 84 \mathrm{wt}$. $\%$ cellulose, compared to only $\leq 70 \mathrm{wt} . \%$ in the NW CNFs. This difference is also expected by the difference in the xylose content of the raw materials (Fig. 2). The obtained residues of the TW were larger and were more hornified than those of the NW (Fig. 10). This difference is consistent with the observed nanofibrillation, as hemicellulose prevents hornification (Iwamoto et al. 2008). The differences in the cellulose content of the nanofibril network thus affect the mechanical behavior of the materials in this study.

\section{Nanomechanical properties}

Nanoindentation testing was performed to compare the hardness of the TW and NW networks and determine whether the variation in the nanofiber characteristics affects the properties perpendicular to the network surface. The results are shown in Fig. 11. The modulus of the NW networks was $8.0 \pm 0.8 \mathrm{GPa}$, whereas that of the TW networks was $7.2 \pm 0.4 \mathrm{GPa}$. The hardness of the NW networks was $0.42 \pm 0.07$ 

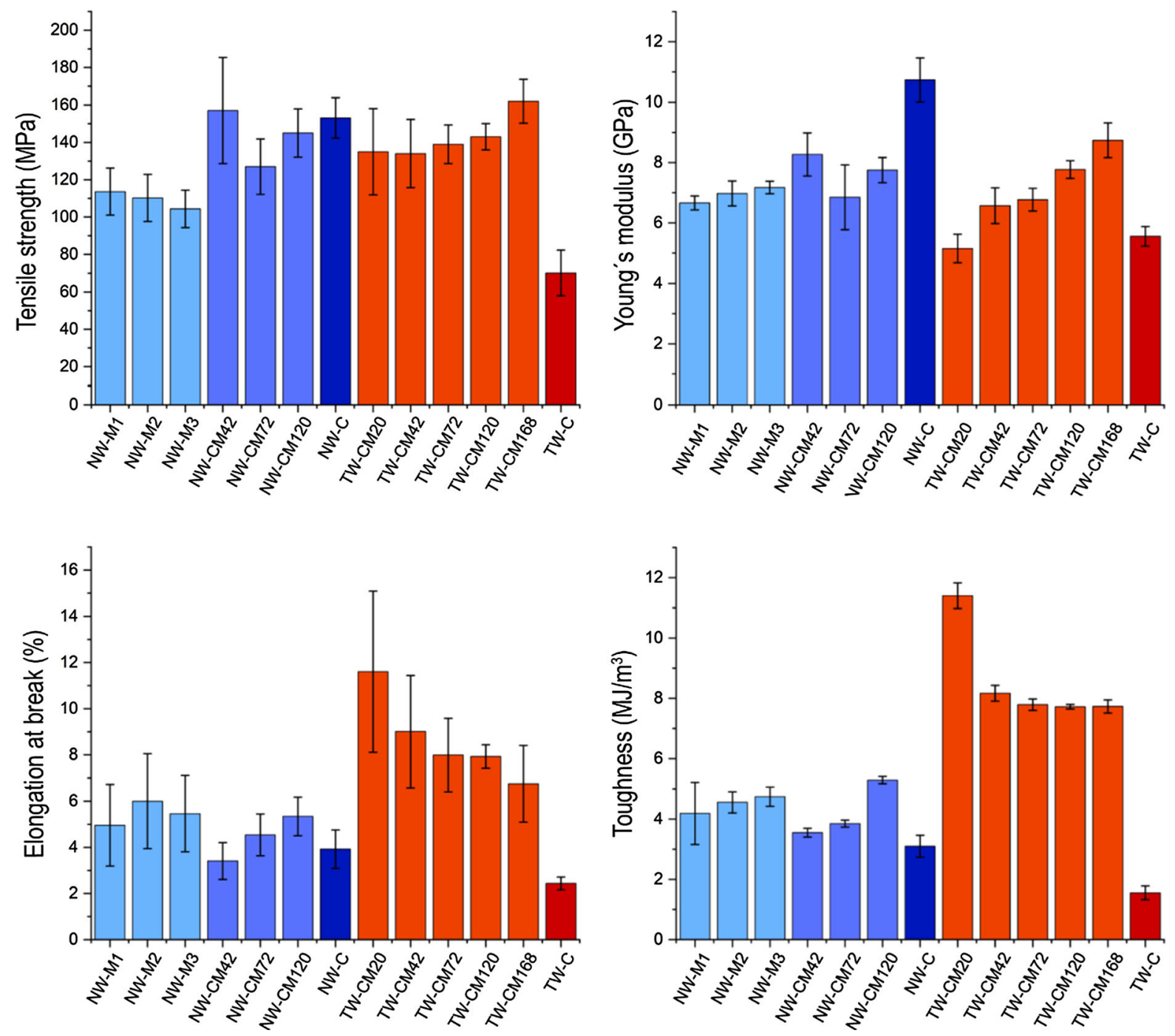

Fig. 9 Mechanical properties of networks prepared from mechanically treated (NW-M and TW-M), chemically treated (NW-C and TW-C), and chemically-mechanically treated (NW-CM and TW-CM) wood samples

$\mathrm{GPa}$, whereas that of the TW network was $0.33 \pm 0.01 \mathrm{GPa}$. The NW networks were thus harder than the TW networks $(p<0.05)$, whereas the modulus difference was not significant $(p<0.108)$.

The lower hardness of some celluloses has been attributed to reduced lateral bonding (Gindl et al. 2006), which could explain the differences between these two types of networks. The reduced bonding can thus be attributed to the presence of larger nanofibrils in the TW networks. Moduli between 12.4 and 15.1 GPa have been reported for other CNF networks from similar cellulosic materials (Yildirim and Shaler
2017), and values of 4.7-8.8 GPa have been reported for cellulose nanocrystal films with a hardness of 0.3-0.5 GPa (Wu et al. 2013). These ranges are similar to those of the networks observed in this study.

\section{Conclusions}

TW and NW from P. tremula (aspen) were subjected to experimental nanofibrillation by mechanical, chemical, and chemical-mechanical processing, which was mediated by direct TEMPO oxidation of the milled wood. The effects of different cellulose content and 


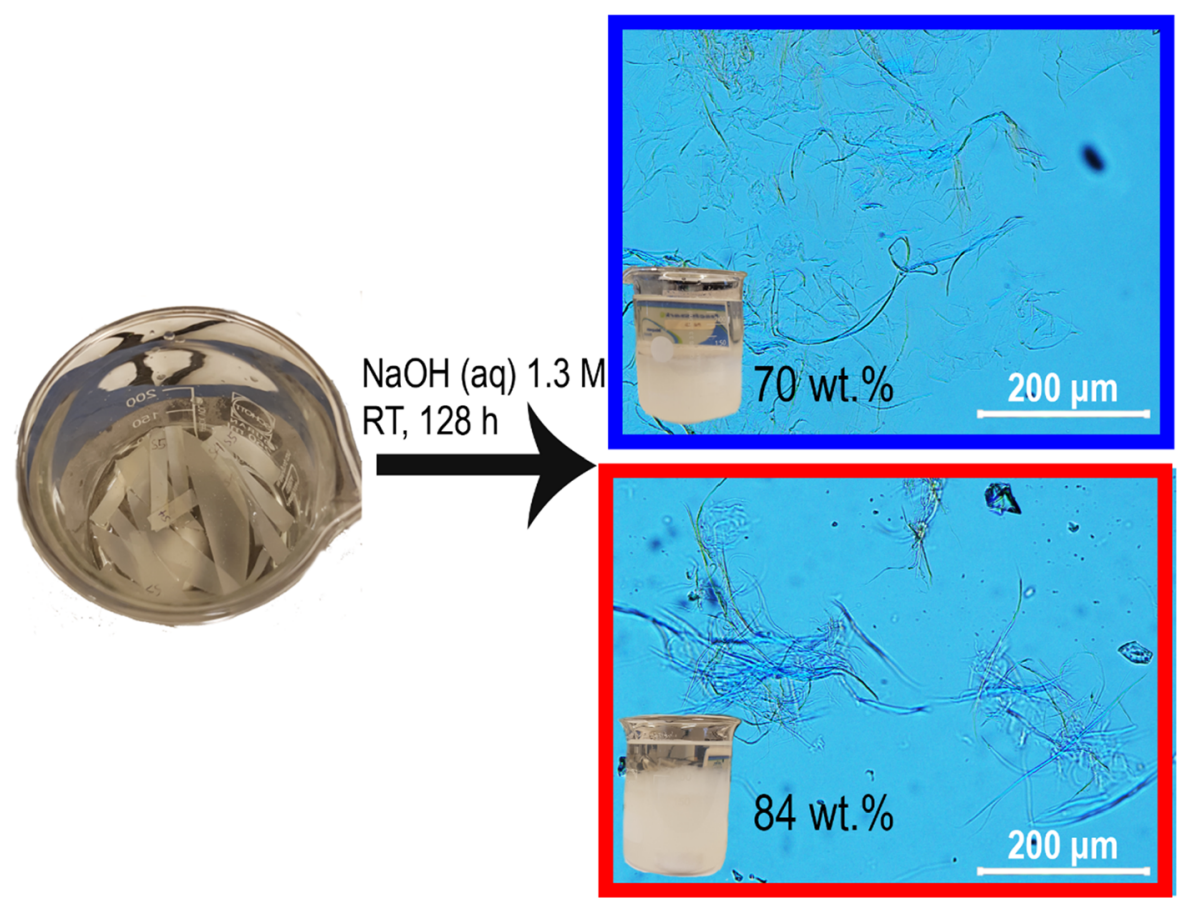

Fig. 10 Optical microscopy images of nanofibril network residues (top, NW; bottom, TW) after reconstitution in sodium hydroxide, which show fibrous components consisting of various fibers, both hornified nanofibril aggregates and native wood cells/residue. A higher cellulose yield and larger fibers appear in the fibril network of TW
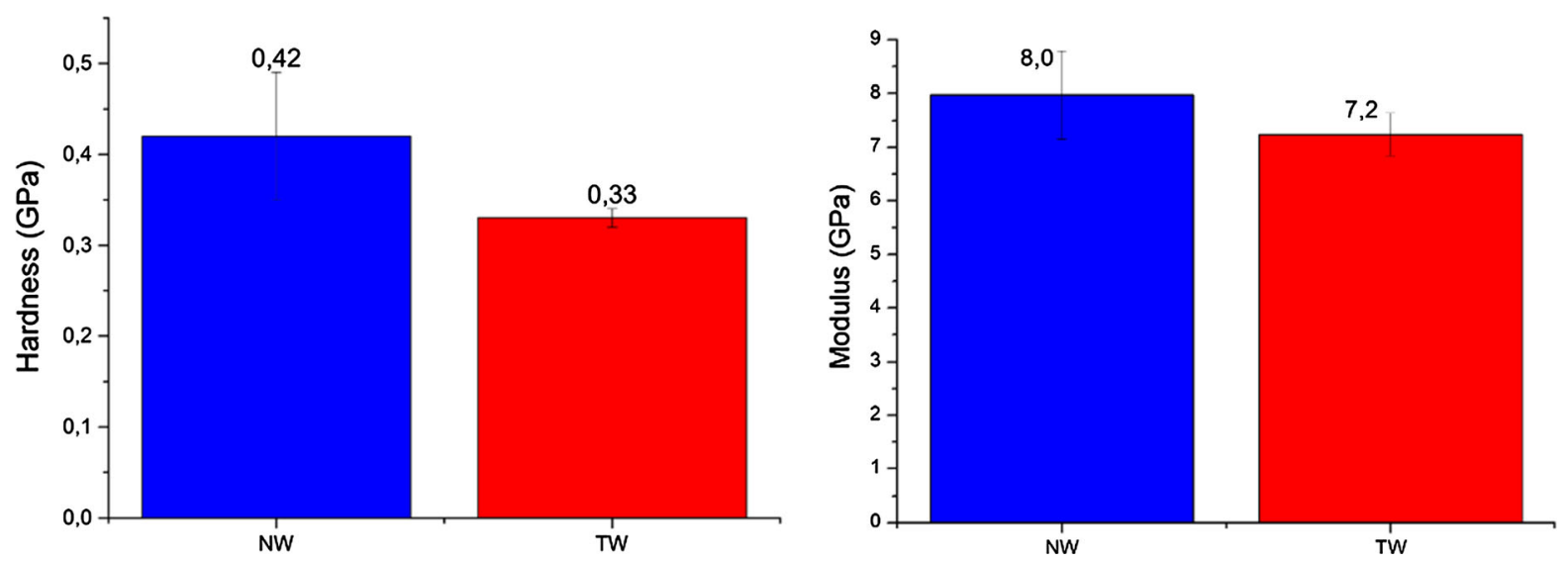

Fig. 11 Hardness (left) and modulus (right) of representative networks consisting of NW CNFs (blue) and TW CNFs (red). The TW CNF networks are significantly softer

cell structure on the obtained nanofibrils and their dense networks were studied. The initial TW wood powder was significantly more difficult to fibrillate despite having lower lignin and hemicellulose contents. The TW resulted in a higher yield of cellulose (65 wt.\% vs. 51 wt.\%) and lower yield of fine CNFs (21 wt.\% vs. 32 wt.\%). The smallest structures from TW had a smaller diameter $(1.18 \pm 0.35 \mathrm{~nm}$, vs.
$1.60 \pm 0.36 \mathrm{~nm}$ for those from the NW; $p<0.05)$. Less fibrillated aggregates $(\geq 10 \mathrm{~nm})$ were more abundant in the TW CNFs than in the NW CNFs. This variation in the fibrillation behavior resulted in decreased transmittance (21.4\% for TW vs. $52.7 \%$ for NW) and viscosity (4.2 mPas for TW vs. $14.5 \mathrm{mPas}$ of NW) of the TW CNF networks and suspensions, respectively. The TW CNF networks exhibited more 
pronounced hornification with higher crystallinity $(85.9 \%$ vs. $78.0 \%)$ and a larger crystallite size (4.0 nm vs. $3.5 \mathrm{~nm})$. The toughness $\left(11.6 \mathrm{MJ} / \mathrm{m}^{3}\right)$ and strain at break (11.4\%) of the TW CNF networks were substantially higher than those of the NW CNF networks (3 MJ/m $\mathrm{m}^{3}$ and $3 \%$, respectively). The NW also yielded networks with a hardness and stiffness of $0.42 \pm 0.07$ and $8.7 \pm 0.90 \mathrm{GPa}$, respectively, compared to values of $0.33 \pm 0.01$ and $7.9 \pm 0.44 \mathrm{GPa}$ for the TW networks. The high cellulose content, crystallinity and more recalcitrant microfibril aggregates of TW balance the enhanced performance of the networks expected from the higher degree of fibrillation for the NW cellulose. These results demonstrate that key characteristics of feedstocks should be considered when correlating systematic differences in wood properties with cellulose and nanofibril behavior using conventional nanocellulose characterization techniques and experimental designs.

Acknowledgments We are grateful for the financial support provided by FORMAS to the Nanowood project (942-2016-10) and by SweTree Technologies, Umeå Sweden, Bio4Energy, the Swedish strategic research program, and Kempestiftelserna.

Funding Open access funding provided by Lulea University of Technology..

Open Access This article is licensed under a Creative Commons Attribution 4.0 International License, which permits use, sharing, adaptation, distribution and reproduction in any medium or format, as long as you give appropriate credit to the original author(s) and the source, provide a link to the Creative Commons licence, and indicate if changes were made. The images or other third party material in this article are included in the article's Creative Commons licence, unless indicated otherwise in a credit line to the material. If material is not included in the article's Creative Commons licence and your intended use is not permitted by statutory regulation or exceeds the permitted use, you will need to obtain permission directly from the copyright holder. To view a copy of this licence, visit http://creativecommons.org/licenses/by/4.0/.

\section{References}

Al-Haddad JM, Kang K-Y, Mansfield SD, Telewski FW (2013) Chemical responses to modified lignin composition in tension wood of hybrid poplar (Populus tremula $\times$ Populus alba). Tree Physiol 33:365-373. https://doi.org/10.1093/ treephys/tpt017

Andersson S, Serimaa R, Paakkari T et al (2003) Crystallinity of wood and the size of cellulose crystallites in Norway spruce (Picea abies). J Wood Sci. https://doi.org/10.1007/ s10086-003-0518-x

Arola S, Malho JM, Laaksonen P et al (2013) The role of hemicellulose in nanofibrillated cellulose networks. Soft Matter. https://doi.org/10.1039/c2sm26932e

Benítez AJ, Torres-Rendon J, Poutanen M, Walther A (2013) Humidity and multiscale structure govern mechanical properties and deformation modes in films of native cellulose nanofibrils. Biomacromol. https://doi.org/10.1021/ bm $401451 \mathrm{~m}$

Charreau H, Foresti ML, Vázquez A (2013) Nanocellulose patents trends: A comprehensive review on patents on cellulose nanocrystals, microfibrillated and bacterial cellulose. Recent Pat Nanotechnol 7:56-80

Das O, Sarmah AK, Bhattacharyya D (2015) Structure-mechanics property relationship of waste derived biochars. Sci Total Environ. https://doi.org/10.1016/j.scitotenv. 2015.08.073

Das O, Hedenqvist MS, Johansson E et al (2019) An all-gluten biocomposite: Comparisons with carbon black and pine char composites. Compos Part A Appl Sci Manuf 120:42-48. https://doi.org/10.1016/J.COMPOSITESA. 2019.02.015

Donaldson LA, Singh AP (2016). In: Kim YS, Funada R, Singh APBT-SXB (eds) Chap. 6-reaction wood. Academic Press, Boston, pp 93-110

Dufresne A (2017) Nanocellulose: from nature to high performance tailored materials, 2nd edn. Walter de Gruyter $\mathrm{GmbH} \& \mathrm{Co} \mathrm{KG}$, Berlin

Foston M, Hubbell CA, Samuel R et al (2011) Chemical, ultrastructural and supramolecular analysis of tension wood in Populus tremula $\mathrm{x}$ alba as a model substrate for reduced recalcitrance. Energy Environ Sci 4:4962-4971. https://doi.org/10.1039/C1EE02073K

Fukuzumi H, Saito T, Okita Y, Isogai A (2010) Thermal stabilization of TEMPO-oxidized cellulose. Polym Degrad Stab 95:1502-1508. https://doi.org/10.1016/j.polymdegradstab. 2010.06.015

Fukuzumi H, Saito T, Isogai A (2013) Influence of TEMPOoxidized cellulose nanofibril length on film properties. Carbohydr Polym 93:172-177. https://doi.org/10.1016/j. carbpol.2012.04.069

Gan Y (2009) Atomic and subnanometer resolution in ambient conditions by atomic force microscopy. Surf Sci Rep 64:99-121. https://doi.org/10.1016/J.SURFREP.2008.12. 001

Geng L, Mittal N, Zhan C et al (2018) Understanding the mechanistic behavior of highly charged cellulose nanofibers in aqueous systems. Macromolecules. https://doi.org/ 10.1021/acs.macromol.7b02642

Gindl W, Konnerth J, Schöberl T (2006) Nanoindentation of regenerated cellulose fibres. Cellulose. https://doi.org/10. 1007/s10570-005-9017-0

Gorshkova T, Mokshina N, Chernova T et al (2015) Aspen tension wood fibers contain $\beta-(1 \longrightarrow 4)$-galactans and acidic arabinogalactans retained by cellulose microfibrils in gelatinous walls. Plant Physiol 169:2048-2063. https:// doi.org/10.1104/pp.15.00690

Henriksson M, Berglund LA, Isaksson P et al (2008) Cellulose nanopaper structures of high toughness. 
Biomacromolecules 9:1579-1585. https://doi.org/10.1021/ bm800038n

Isogai A, Kato Y (1998) Preparation of polyuronic acid from cellulose by TEMPO-mediated oxidation. Cellulose 5:153-164. https://doi.org/10.1023/A:1009208603673

Isogai T, Saito T, Isogai A (2011) Wood cellulose nanofibrils prepared by TEMPO electro-mediated oxidation. Cellulose 18:421-431. https://doi.org/10.1007/s10570-010-9484-9

Iwamoto S, Abe K, Yano H (2008) The effect of hemicelluloses on wood pulp nanofibrillation and nanofiber network characteristics. Biomacromolecules 9:1022-1026. https:// doi.org/10.1021/bm701157n

Iwamoto S, Lee S-H, Endo T (2014) Relationship between aspect ratio and suspension viscosity of wood cellulose nanofibers. Polym J 46:73-76. https://doi.org/10.1038/pj. 2013.64

Jiang J, Ye W, Liu L et al (2017) Cellulose nanofibers prepared using the TEMPO/Laccase/O2 system. Biomacromolecules 18:288-294. https://doi.org/10.1021/acs. biomac.6b01682

Jonasson S, Bünder A, Niittylä T, Oksman K (2020) Isolation and characterization of cellulose nanofibers from aspen wood using derivatizing and non-derivatizing pretreatments. Cellulose. https://doi.org/10.1007/s10570-01902754-w

Jonoobi M, Mathew AP, Oksman K (2012) Producing low-cost cellulose nanofiber from sludge as new source of raw materials. Ind Crops Prod. https://doi.org/10.1016/j. indcrop.2012.03.018

Li Q, Renneckar S (2009) Molecularly thin nanoparticles from cellulose: isolation of sub-microfibrillar structures. Cellulose. https://doi.org/10.1007/s10570-009-9329-6

Li Q, Renneckar S (2011) Supramolecular structure characterization of molecularly thin cellulose i nanoparticles. Biomacromolecules. https://doi.org/10.1021/bm101315y

Li J, Wei X, Wang Q et al (2012) Homogeneous isolation of nanocellulose from sugarcane bagasse by high pressure homogenization. Carbohydr Polym 90:1609-1613. https:// doi.org/10.1016/j.carbpol.2012.07.038

Li P, Sirviö JA, Haapala A, Liimatainen H (2017) Cellulose nanofibrils from nonderivatizing urea-based deep eutectic solvent pretreatments. ACS Appl Mater Interfaces 9:2846-2855. https://doi.org/10.1021/acsami.6b13625

Lichtenstein K, Lavoine N (2017) Toward a deeper understanding of the thermal degradation mechanism of nanocellulose. Polym Degrad Stab 146:53-60. https://doi. org/10.1016/j.polymdegradstab.2017.09.018

Linow K-J (1985) Wood: Chemisry, Ultrastructure, Reactions. von D. FENGEL und G. WEGENER. ISBN 3-11-0084813. Berlin/New York: Walter de Gruyter 1984. XIII, 613 S., 351 Abb., 124 Tab., 2816 Lit., geb. DM 245,-. Acta Polym 36: 295. https://doi.org/10.1002/actp.1985.010360515

Mao R, Goutianos S, Tu W et al (2017) Modelling the elastic properties of cellulose nanopaper. Mater Des. https://doi. org/10.1016/j.matdes.2017.04.050

Mellerowicz EJ, Gorshkova TA (2011) Tensional stress generation in gelatinous fibres: a review and possible mechanism based on cell-wall structure and composition. J Exp Bot 63:551-565. https://doi.org/10.1093/jxb/err339

Mendoza L, Gunawardhana T, Batchelor W, Garnier G (2018) Effects of fibre dimension and charge density on nanocellulose gels. J Colloid Interface Sci. https://doi.org/ 10.1016/j.jcis.2018.04.077

Meng Q, Wang TJ (2019) Mechanics of strong and tough cellulose nanopaper. Appl Mech Rev 71(4):040801-040831. https://doi.org/10.1115/1.4044018

Meng Q, Li B, Li T, Feng XQ (2017) A multiscale crackbridging model of cellulose nanopaper. J Mech Phys Solids. https://doi.org/10.1016/j.jmps.2017.03.004

Müller M, Burghammer M, Sugiyama J (2006) Direct investigation of the structural properties of tension wood cellulose microfibrils using microbeam X-ray fibre diffraction. In: Holzforschung

Nečas D, Klapetek P (2012) Gwyddion: an open-source software for SPM data analysis. Cent Eur J Phys 10:181-188. https://doi.org/10.2478/s11534-011-0096-2

Park S, Baker JO, Himmel ME et al (2010) Cellulose crystallinity index: measurement techniques and their impact on interpreting cellulase performance. Biotechnol Biofuels. https://doi.org/10.1186/1754-6834-3-10

Pettersen RC (1984) The chemical composition of wood. In: Rowell R (ed) Chemistry of solid wood. American Chemical Society, Washington, DC, pp 57-126

Purushotham P, Ho R, Zimmer J (2020) Architecture of a catalytically active homotrimeric plant cellulose synthase complex. Science. https://doi.org/10.1126/science. abb2978

Saito T, Kimura S, Nishiyama Y, Isogai A (2007) Cellulose nanofibers prepared by TEMPO-mediated oxidation of native cellulose. Biomacromolecules 8:2485-2491. https:// doi.org/10.1021/bm0703970

Saito T, Hirota M, Tamura N et al (2009) Individualization of nano-sized plant cellulose fibrils by direct surface carboxylation using TEMPO catalyst under neutral conditions. Biomacromolecules 10:1992-1996. https://doi.org/ 10.1021/bm900414t

Sawada D, Kalluri UC, O'Neill H et al (2018) Tension wood structure and morphology conducive for better enzymatic digestion. Biotechnol Biofuels. https://doi.org/10.1186/ s13068-018-1043-x

Scherrer P (1918) Bestimmung der Größe und der inneren Struktur von Kolloidteilchen mittels Röntgenstrahlen. Nachrichten von der Gesellschaft der Wissenschaften zu Göttingen, Math Klasse

Segal L, Creely JJ, Martin AE, Conrad CM (1959) An empirical method for estimating the degree of crystallinity of native cellulose using the x-ray diffractometer. Text Res J. https:// doi.org/10.1177/004051755902901003

Sehaqui H, Ezekiel Mushi N, Morimune S et al (2012) Cellulose nanofiber orientation in nanopaper and nanocomposites by cold drawing. ACS Appl Mater Interfaces. https://doi.org/ 10.1021/am2016766

Shibata I, Isogai A (2003) Depolymerization of cellouronic acid during TEMPO-mediated oxidation. Cellulose. https://doi. org/10.1023/A:1024051514026

Shinoda R, Saito T, Okita Y, Isogai A (2012) Relationship between length and degree of polymerization of TEMPOoxidized cellulose nanofibrils. Biomacromolecules 13:842-849. https://doi.org/10.1021/bm2017542

Stelte W, Sanadi AR (2009) Preparation and characterization of cellulose nanofibers from two commercial hardwood and 
softwood pulps. Ind Eng Chem Res. https://doi.org/10. 1021/ie9011672

Sweeley CC, Bentley R, Makita M, Wells WW (1963) Gasliquid chromatography of trimethylsilyl derivatives of sugars and related substances. J Am Chem Soc 85:2497-2507. https://doi.org/10.1021/ja00899a032

Timell TE (1969) The chemical composition of tension wood. Sven PappTidn 72:173-181

Usov I, Nyström G, Adamcik J et al (2015) Understanding nanocellulose chirality and structure-properties relationship at the single fibril level. Nat Commun. https://doi.org/ 10.1038/ncomms8564

Wise LE, Murphy M, D’Addieco A (1947) Chlorite holocellulose, its fractionation and bearing on summative wood analysis and studies on the hemicelluloses. Pap trade $\mathbf{J}$ 122:35-43

Wu Y, Wang S, Zhou D et al (2010) Evaluation of elastic modulus and hardness of crop stalks cell walls by nano- indentation. Bioresour Technol. https://doi.org/10.1016/j. biortech.2009.10.074

Wu Q, Meng Y, Concha K et al (2013) Influence of temperature and humidity on nano-mechanical properties of cellulose nanocrystal films made from switchgrass and cotton. Ind Crops Prod 48:28-35. https://doi.org/10.1016/j.indcrop. 2013.03.032

Yildirim N, Shaler S (2017) A study on thermal and nanomechanical performance of cellulose nanomaterials $(\mathrm{CNs})$. Materials (Basel). https://doi.org/10.3390/ma10070718

Zhu H, Zhu S, Jia Z et al (2015) Anomalous scaling law of strength and toughness of cellulose nanopaper. Proc Natl Acad Sci U S A. https://doi.org/10.1073/pnas.1502870112

Publisher's Note Springer Nature remains neutral with regard to jurisdictional claims in published maps and institutional affiliations. 